\title{
BUTLER, JUDITH “CUERPOS ALIADOS Y LUCHA POLÍTICA. HACIA UNA TEORÍA PERFORMATIVA DE LA ASAMBLEA
}

\author{
RESEÑA DEL LIBRO: Butler, Judith, Cuerpos aliados y lucha politica. Hacia una \\ teoría performativa de la asamblea, Paidós, Buenos Aires, 2017. (256 p.)
}

Camila Arbuet

En este libro Judith Butler reúne un significativo conjunto de reflexiones teórico políticas sobre los temas que han sido el centro de sus preocupaciones desde hace al menos una década. Se trata de una serie de intervenciones, armadas como capítulos, que han sido parte de sus exposiciones en seminarios en diversas universidades desde el 2010.

Este es claramente un escrito pensado para la intervención política inmediata, donde sus reflexiones respecto del vínculo entre performatividad, vulnerabilidad y asamblea están puestas al servicio de inteligir las formas de "actuación" del activismo político existente. Es decir, se propone volver sobre los presupuestos que están implícitos en los actos colectivos de autodefensa - de vínculo activo a través de la vulnerabilidad compartida-, previos a cualquier explicitación/reclamo por/de los derechos, sentidos y principios de esa decisión. En sus palabras: “(...) a veces lo más importante no es el poder que uno tiene y que le faculta para actuar; a veces, lo que hay que hacer es actuar, y a partir de esa actuación reclamar el poder que uno necesita." (p. $63)$.

En este sentido, es un texto de una inmediatez absoluta, que sirve como herramienta para desnaturalizar las prácticas de reunión y movilización, de resistencia y protesta, en condiciones de extrema precariedad. Esto se nota tanto en el estilo de escritura de sus exposiciones - despojado, conciso y provocativo-, que tienen evidentes pretensiones pedagógicas, como en el esfuerzo constante que hace el texto por tensionar movimientos y descripciones de coyuntura con partes centrales de su compleja matriz filosófica. Partes desarrolladas especialmente en El género en disputa (1989); Cuerpos que importan (2002); Vida precaria (2004); Dar cuenta de sí mismo (2005) y Marcos 
de guerra (2010). Así es como el libro recoge diversas experiencias de "aparición" (torcionando el concepto arendtiano) y organización política en situaciones límite propias del proceso de "desposesión" (Butler y Athanasiou, 2017) salvaje al que nos somete la contemporaneidad neoliberal; experiencias que van desde las manifestaciones de Ferguson en 2014 (tras las olas de gatillo fácil de la policía contra la población negra) a los diferentes movimientos okupa, pasando por las formas de asamblea en Palestina, Turquía y Egipto.

El texto inicia su recorrido haciendo una clara síntesis de su teoría de la performatividad, en su relación con el género, revisitando su ya clásico camino de Austin a Kosofsky Sedgwick; a fin de hacer foco críticamente en el reconocimiento como mecanismo de constitución de la esfera pública, preguntándose ¿Qué se cuenta como "pueblo"? - problema en el que resuena en su debate con Spivak ¿Quién le canta al Estado-Nación? (2009)- ¿Cómo se cambia la relación entre lo reconocible y lo que no lo es? ¿Cuáles son los límites de la esfera pública para expresar el poder de los cuerpos reunidos, más allá de lo éstos “digan”? El primer capítulo tiene idas y venidas sobre estos tópicos que incluyen un intento por deconstruir la idea de responsabilidad basada en la autonomía individual y el empresariado de sí. Frente a la culpabilización liberal que atraviesa esa concepción de responsabilidad, Butler plantea el proceso de responzabilización que generan las asambleas públicas en los cuerpos implicados. Hacia la mitad del primer capítulo aparece quien será la pensadora que la autora escogió como alter encargada de mantener la tensión teórica de todo el texto: Hannah Arendt.

El vínculo que nos propone Butler con la obra de Arendt es altamente conflictivo, donde mientras rescata elementos centrales de su teoría como el derecho de aparición o la generación de lo público a través de la pluralidad, esgrime una crítica feroz sobre las vetas más liberales de la filosofía arendtiana señalando -entre varias cosas más-: cómo allí el cuerpo queda por fuera del acto de habla político estando atado a la necesidad biológica; cómo la distinción entre cuerpo y mente deja a los cuerpos feminizados exentos de la esfera pública (crítica que ya tiene una cierta trayectoria en las feministas lectoras de La condición humana); cómo la lucha por sobrevivir no forma parte de la vida misma.

Por lo visto, Arendt considera que quienes actúan impulsados por la necesidad actúan con el cuerpo, pero la necesidad no puede nunca ser una forma de libertad, y por otra 
parte apunta que la libertad solo puede alcanzarla quienes, en definitiva, no padecen hambre ¿Y qué sucedería entonces si uno está hambriento e indignado, siendo un individuo libre y razonante, y surge un movimiento político que combate la desigualdad en el reparto de los alimentos? (pp. 52-53).

El segundo capítulo está destinado a pensar la lógica de las alianzas y la toma de las calles, principalmente en las movilizaciones multitudinarias -es imposible en este punto no tener en mente todo el tiempo el $8 \mathrm{M}-$, como estrategia material de construcción de un espacio colectivo físico con ciertas características -por ejemplo, libre de policías-. Constantemente, el texto vuelve sobre la premisa de la primera cita que usamos, es decir, sobre la tensión entre las condiciones materiales de (im)posibilidad "en", "durante" y "después" de la acción (deliberando cómo cada uno de estos tres momentos signa, en un ida y vuelta, la actuación) y la persistencia e invención en la resistencia. Esto nos lleva a discusión sobre la precariedad y la vulnerabilidad (temas de los capítulos tres y cuatro), donde los links con la teoría levinasiana se hacen explícitos. Finalmente, el trabajo cierra con un conjunto de disquisiciones ético políticas sobre la inscripción social de la "vida buena", que se hacen retomando a Adorno, en una línea semejante a la que había comenzado a trazarse en Dar cuenta de sí mismo... sumándole ahora la disputa con Arendt.

Cuerpos aliados y lucha política es, por las peculiares características de sus movimientos argumentales, un excelente libro para iniciarse en la prolífera e interesante obra de Judith Butler. Es un texto donde nos queda muy claro desde sus primeras páginas que estamos no solo ante la obra de una gran pensadora sino también de una excepcional docente, preocupada por inteligir, reflexionar y activar la indignación y la resistencia colectivas. 
Cuadernos Filosóficos. Segunda Época, XIV, 2017 